\title{
An Analysis on the Individual Needs of English-major Students Under the Background of the Reform
}

\author{
Shufen Yang \\ Wuchang Shouyi University, Wuhan 430064, China.
}

Keywords: the individual needs, English majors, core competence

\begin{abstract}
The enactment of "the Undergraduate Specialty Teaching Quality of Higher Institutions in National Standard " provides evidence for each career development. The national standard not only highlights learner-centered teaching and output, but also emphasizes the student's subjectivity in education, which are bound to enhance deepening reform of all majors that include English. The analysis of students' needs can make personnel training more targeted and help students achieve graduation requirements better, and then finally students will become the personnel needed by the society. This paper takes English-major students of general university as the research object. It studies the individual needs of English-major students, which consists of the learning ability gap between learners and learner's individual desire, the needs of learning process and environment needs to optimize major construction.
\end{abstract}

\section{Introduction}

The enactment of "the Undergraduate Specialty Teaching Quality of Higher Institutions in National Standard " provides evidence for each career development. The national standard not only highlights learner-centered teaching and output, but also emphasizes the student's subjectivity in education. On the one hand, this orientation requires schools and teachers to take students as the research object to study the learning characteristics and individual learning needs of them. On the other hand, graduates are educated by universities and examined in the market. Their core competitiveness reflects the specialty educating level. In order to seek the long-term construction of the specialty and cultivate the graduates with requirements, it is significant to analyze the subjectstudents. This paper mainly analyzes the individual needs of English-major students in regular colleges so as to promote the development of English majors and promote the reform of professional curriculum, teaching methods, syllabus and personnel training.

\section{Demand analysis}

The analysis on the individual needs of students is one aspect of demand. Demand analysis generally refers to the technology and methods of studying requirements through various means such as introspection, interview, observation, questionnaire, testing [1]. At present, the demand analysis models mainly consist of Goal-Oriented Requirement Analysis, Scenario Analysis, target demand and learning demand of Hutchinson \& Waters as well as comprehensive demand analysis model of Dudley-Evans \& St. John 's model. Target scenario analysis focuses on the use of language. At present, it emphasizes the process needs of the learners and the gap between the current and the target language level of the learners. The requirement analysis model of Hutchinson \& Waters not only values the use of language, but also subdivides the target needs into basic knowledge, knowledge ignored and knowledge targeted. The learning needs include the learning environment, knowledge and skills, strategies and motivation of the learners [2]. The domestic scholar Dingfang Shu combines theories and models of needs analysis conducted in other countries and believes that the need is divided into social need and individual need. The former refers to foreign language skills of relevant personnel which social and employers demand, and the latter is about the gap between the actual level and the level that students expect [3]. Social needs have evolved from the target needs. The object of the situation needs analysis is the learner. This article focuses on the latter and 
analyses the individual needs of the learners.

\section{Core Competence}

The concept of the Core Competence was first proposed by the American academic Prahalad and British scholar Hamel [4]. And it shows three main characteristics: the value which customers need; the uniqueness which is not easily imitated by competitors; the ductility which can be applied to various tasks at the same time so that the enterprise can meet the customer needs in a large range.[5] The professional Core Competence is the unique competitiveness belonging to different universities and different specialties, which greatly influences the existence and development of specialty. [6] The Competence of English Majors has a direct impact on the long-term development of the specialty in the market. The analysis on the individual needs of students will help reduce the gap between the target needs and the current situation, and then improve students' market competitiveness.

\section{An analysis on the individual needs of the learners}

This study is mainly based on the theory of needs analysis both overseas and in China, especially the analysis model presented by Dingfang Shu and some interviews conducted by the researcher. The researcher has designed a questionnaire for individual needs analysis. 208 English major students from five colleges and universities are randomly chosen as the participants of the study. This paper studies the individual needs of English-major students, which consists of the learning ability gap between learners and learner's individual desire, the needs of learning process and environment needs.

\subsection{Learning ability gap of learners}

$53 \%$ of the students spent 2 hours on learning English after class per week, 18\% of the students spend more than 10 hours after class, $16 \%$ of them are 6 hours, 13\% of them are 4 hours. It means that each day more than half of the students study English for at most 20 minutes after class.

In English learning, many students feel they are poor at grammar and vocabulary, and unable to understand hard sentences. They lack cultural background knowledge and dare not speak English. Lack of grammar knowledge makes it difficult for students to understand materials which are difficult and long.

In self-assessment of English level, 92\% of students think that they can understand the Standard English at normal speed. Secondly, they can deliver English speech and find the necessary information after reading English texts. It means that students are more confident in listening, speaking and reading, but poor in oral and written English, so they cannot communicate with native speakers freely.

\subsection{Individual aspirations of learners}

$66 \%$ of students want to improve their speaking skills, and then reading, translating, writing and listening which reflect that students develop much more confidence in listening. Those students choose English as their major for several reasons. 75\% students major in English out of personal interest, and $55 \%$ of the students just expect to find a good job after graduation. $53 \%$ students want to improve their speaking, while $45 \%$ of the students hope to improve personal accomplishment and then have a better understanding of culture and lifestyle by learning the language; only a few students just expect to get a degree.

The targeted fields of work after graduation are business, education and tourism. Fewer students choose to engage in oral translation or research. This result can provide some guidance for curriculum design and reform in English.

\subsection{The needs of learning process}

In the process of learning English language, what arouse students' interest most in English include interesting topic (68\%), high achievement of learning (53\%), and diversity training (42\%). Surprisingly, rich teaching content (18\%), class participation (24\%), a harmonious atmosphere of learning (29\%), the personal charm of teacher (29\%), the human edification (32\%) cannot 
effectively stimulate students' interest. So Those that can stimulate students' internal drive such as interesting content and learning satisfaction can make students learn more effectively.

In the selection of learning strategies, the students love learning English by watching movies, television dramas, documentaries in the first place, some as high as $95 \%$. $71 \%$ of the students prefer to communication of the target language, and $55 \%$ of the students choose to listen to the news broadcast and English songs. They don't like to learn English by memorizing or reviewing in time but prefer to rise through the way of video input, while the traditional way of memorizing or reviewing is abandoned.

\subsection{The needs of learning environment}

Results of the analysis of teachers' role, teaching mode, extracurricular activities, learning resources, assessment forms, teaching materials, curriculum, teaching contents and the fostering objectives are as follows.

The role of teachers. Most students want teachers to be motivators, evaluators of learning process and assistor, which account for 32\%, 32\% and 21\% respectively. Only 5\% of them want teachers to be trainers. Students are more fond of passionate teachers(61\%), teachers who can employ different teaching methods flexibly(58\%), arouse students' interest (55\%) and care about students(50\%). On the contrary, teachers with good language competence, wide range of knowledge and a strong sense of responsibility cannot attract students to a great extent.

Class teaching mode. Half of the students like task-based language class and prefer to learn as a group and expect the teacher to be a monitor. $74 \%$ of the students prefer teachers to teach in English in the class. Only some of the students with weak language competence want teachers to explain more in Chinese.

Extracurricular activities. Among all extracurricular activities, 53\% of the students reckon that being a volunteer and helping foreigners can best improve their language proficiency. The second comes to competitions such as English dramas, speaking competitions and English corner activities followed by with a ratio of $21 \%$ and $16 \%$ respectively. Learning resources. $95 \%$ of the students choose English movies. 74\% and 71\% of them consider English application softwares and English songs as main learning resources. The minority of students learn the language by reading English novels(3\%) or newspapers and magazines (8\%). Currently, English majors are more likely to learn through audio and video multimedia resources, and only a small number of students try to improve their comprehensive abilities by reading more books.

Assessment model.79\% of the students hold the opinion that a combination of formative assessment and final assessment should be adopted and a considerable number of students (61\%) consider that the rate of formative assessment should be higher. Application of teaching materials. More than half of the students (76\%) hope that teachers can spend less time on the teaching materials, but add more extracurricular knowledge.

Curriculum provision. Most students think oral English and listening courses are most important, with $92 \%$ and $71 \%$ respectively. Then the second comes to courses of commerce and trade, translation courses and practice courses, which occupy 40\%, 37\% and 37\% respectively. Students attach less importance to reading courses and courses introducing culture and literature of other countries. Interestingly, when students launch self-evaluation, they think that the obstacles in language learning include lower reading ability and devoid of related background knowledge. While such courses mentioned above can remedy these shortcomings. However, students think that such courses are least important than others. This result indicates that students generally attach more importance to language skills, especially listening and speaking courses, but ignore the role of humanities courses.

Teaching content. 84\% of the students think that the improving of comprehensive ability, such as communication ability, cooperation ability, organization ability should be the focus of teaching. $74 \%$ of the students reckon that learning and application of language skills should be emphasized, while $68 \%$ of the students attach more importance to English specialty knowledge, especailly knowledge related to trade, translation, education methodology.

Cultivation objectives. Most students (90\%) think that universities should focus on improving 
students' English listening and speaking ability first. About 55\% of the students assume that critical thinking and innovative abilities are more important than translation ability, autonomous learning ability and problem-solving ability. Reading and team cooperation abilities are relatively less valued.

The final part of the questionnaire is a subjective item, which requires students to make suggestions or proposal on professional construction of the school. Most of the suggestions put poward by students concentrate on curriculum design, teaching methods, teaching contents, curriculum evaluation, extracurricular activities, and ability training and so on. It is proposed that the proportion of listening and speaking courses and practice courses should be increased, with emphasis on the cultivation of students' oral expression ability. Time breakdown of specialized direction should be advanced to demonstrate specialization. Flexible teaching methods and interesting teaching content can stimulate students' interest in learning.

\section{Conclusion}

From the analysis of students' personal demands, it can be found that there is a gap between the learners' current situational demands and their targeted needs. Learners generally think that they have lower language proficiency. Listening and reading are relatively strong, while speaking, translating and writing are relatively weak. They are eager to improve oral skills and then reading, translation, writing and listening skills. With regard to the needs of the learning process, the traditional methods of reciting and memorizing have been eliminated, and students tend to learn through multimedia resources or by communicating with native speakers from English-speaking countries. Interesting topics, the high sense of achievement in learning and a variety of activities can most enhance the interest in learning.

Students expect teachers to be the motivators, evaluators of learning process and effects and facilitators of learning. They also believe that formative assessment and final assessment should be combined, and formative assessment should occupy a larger proportion. In addition to language skills, students also hope to improve their comprehensive skills, such as communication, cooperation, organizational thinking and innovation in the learning process.

The individual needs of students are consistent with national policies in some respects. For example, it is stated in the General Standards for the Accreditation of Undergraduate Majors in Ordinary Colleges and Universities (HUMANITIES AND SOCIAL SCIENCES) that in addition to the basic professional skills, we should emphasize the attributes of "people" and pay attention to the cultivation of students' soft abilities, such as humanistic literacy, communication and expression, teamwork, speculative innovation and so on. These new changes require schools and teachers to re-examine all aspects of the teaching process, continue to explore and attempt and sustain improvement in order to promote the efficiency of talent training and enhance the core competitiveness of students so that graduates can meet the professional quality training standards and satisfy the needs of the country and society.

\section{References:}

[1]. Bingbing Chen. Theoretical Construction of College English demand Analysis Model [J] Foreign Language Research 2010(2):120-123.

[2]. Hutchinson, T. \& Water, A. English for Specific Purposes-A Learning-centred Approach [M] Cambridge CUP, 1987.

[3]. Shu Dingfang. Foreign language Teaching Reform: Problems and countermeasures [M] Shanghai Foreign Language Education Press.

[4]. Prahalad, C. K. \& Hamel, G. The Core Competence of the Corporation [J]. Harvard Business Review, 1990 (3) :79-91.

[5]. Guanfu Wang, Li Liu. Theoretical discussion on the Core Competitiveness of Business English 
[J] FLC Journal, 2012(5):11-19.

[6]. Jizhi Ruan. From the perspective of the core competence of business English majors, its teaching focus[J] Journal of Zhejiang University of Technology, 2013(3):307-311. 